\title{
EL CAMINO HACIA EL “FINAL DEL HUMANISMO”. CRÍTICA DE LA ILUSTRACIÓN Y DEL ROMANTICISMO EN HANNAH ARENDT
}

\author{
The Course Towar the "End of Humanism". Critique of Enlightenment and Romanticism in Hannah Arendt
}

Anabella Di Pego ${ }^{1}$

\begin{abstract}
RESUMEN
En este trabajo procuramos esclarecer el posicionamiento arendtiano frente a la modernidad en su obra temprana hasta comienzos de la década del cincuenta. Para ello, reconstruimos la crítica de la Ilustración y del Romanticismo en relación con el antisemitismo moderno y el surgimiento del pensamiento racial en su libro sobre el totalitarismo. Nuestra hipótesis de lectura es que en la perspectiva de Arendt estas corrientes intelectuales aunque con diferencias notables comparten un modo de tratamiento de los otros, que es propio de la matriz liberal moderna, en donde no es posible la persistencia de los individuos y pueblos que no responden a la norma social y cultural dominante. Sostenemos así que ciertas concepciones de la Ilustración y del Romanticismo desempeñan un papel nodal para comprender el advenimiento del totalitarismo del siglo $\mathrm{XX}$, y más en general, del problema de los refugiados y las minorías que atraviesa todo el siglo pasado hasta nuestros días.
\end{abstract}

Palabras clave: modernidad, antisemitismo, racismo, liberalismo.

\section{ABSTRACT}

In this work I try to clarify the Arendtian position on modernity in her early work until the beginning of the fifties. I reconstruct the critique of Enlightenment and Romanticism in relation to modern anti-Semitism and the rise of racial thinking in her book on totalitarianism. The hypothesis is that these intellectual movements, although with notable differences, share in Arendt's perspective a way of treating others. This proceed is typical of the modern liberal matrix, where isn't possible the persistence of individuals and peoples that don't accord to the social norm and the dominant culture. I thus maintain that certain conceptions of the Enlightenment and Romanticism play a nodal role in understanding the advent of the totalitarianism of the twentieth century, and more generally, of the problem of refugees and minorities over the last century until our days.

Keywords: modernity, ant-Semitism, racism, liberalism.

\section{RESUMO}

Neste artigo, tentamos esclarecer a posição arendtiana sobre a modernidade em seus primeiros trabalhos até o início dos anos cinquenta. Para fazer isso, reconstruímos a crítica do Iluminismo e do Romantismo em relação ao antisemitismo moderno e à ascensão do pensamento racial em seu livro sobre totalitarismo. Nossa hipótese de leitura é que, da perspectiva de Arendt, essas correntes intelectuais, embora com diferenças notáveis, compartilham uma maneira de tratar os outros. Esse procedimento é típico da matriz liberal moderna e não permite a persistência de indivíduos e povos que não respondem à norma social e cultural dominante. Portanto, sustentamos que certas concepções do Iluminismo e do Romantismo desempenham

\footnotetext{
1 Anabella Di Pego es Investigadora del Consejo Nacional de Investigaciones Científicas y Técnicas (CONICET) y docente en el Departamento de Filosofía (FaHCE) de la Universidad Nacional de La Plata (UNLP) y en la Maestría en Filosofía de la Universidad Nacional de Quilmes (UNQ), República Argentina. Es Profesora y Licenciada en Filosofía, Magíster en Ciencias Sociales y Doctora en Filosofía por la Universidad Nacional de La Plata. Ha sido becaria del Servicio Alemán de Intercambio Académico (DAAD) y en este marco realizó dos estancias breves en Alemania (2008 y 2013) y una estancia anual de investigación en la Freie Universität Berlin (2010-2011). Ha realizado una estadía de investigación en la Universitat de Barcelona (2016) con la Profesora Fina Birulés. Sus áreas de interés son la filosofía contemporánea, la hermenéutica, la teoría crítica y el pensamiento político contemporáneo. Ha publicado numerosos artículos en reconocidas revistas académicas nacionales e internacionales y es autora de los libros La modernidad en cuestión. Totalitarismo y sociedad de masas en Hannah Arendt (2015) y Politica y filosofía en Hannah Arendt. El camino desde la comprensión hacia el juicio (2016).
} 
um papel nodal na compreensão do advento do totalitarismo do século XX e, em geral, do problema de refugiados e minorias que surgiram no século passado e persistem até o presente.

Palavras-chave: modernidade, antisemitismo, racismo, liberalismo.

\section{INTRODUCCIÓN}

Los estudios sobre el abordaje arendtiano del totalitarismo y su inscripción en la modernidad han enfatizado el papel de las prácticas y de la perspectiva histórica de aproximación a los procesos sociales, políticos y económicos en el advenimiento de este fenómeno del siglo pasado. Así, Margaret Canovan considera que el análisis de Arendt otorga "menos énfasis a la influencia de las ideas y mucho más al establecimiento de prácticas"2. De este modo, los trabajos sobre el totalitarismo y el derrotero de la modernidad no se han concentrado en el papel de las corrientes intelectuales de la época. Por nuestra parte, procuramos mostrar la relevancia de la Ilustración y del Romanticismo en el posicionamiento de Arendt frente a la modernidad hasta comienzos de la década del cincuenta. Sostenemos que el análisis arendtiano de la modernidad implica una amalgama de elementos provenientes del plano material y de la tradición intelectual, que luego convergen en la emergencia del totalitarismo ${ }^{3}$.

En el primer apartado, nos detendremos en el vínculo entre la Ilustración y el antisemitismo moderno a partir del modo de concebir a los individuos y pueblos que no responden a la norma social dominante. En el segundo apartado, analizaremos el papel del Romanticismo en el surgimiento del pensamiento racial consagrado con el auge del imperialismo. A pesar de sus divergencias, la Ilustración y el Romanticismo compartirían una concepción de los otros y de las minorías, propia del liberalismo moderno y que se encontraría a la base del antisemitismo y del pensamiento racial. Bernstein ha estudiado el "legado de la Ilustración y del liberalismo clásico"4 en el tratamiento de la cuestión judía, sin embargo, en su libro apenas encontramos algunas referencias acotadas al Romanticismo5.

\footnotetext{
${ }^{2}$ CANOVAN, Margaret. Hannah Arendt. A Reinterpretation of her Political Thought. Cambridge: Press Syndicate of the University of Cambridge, 2002, p. 23. La traducción me pertenece en esta y en las sucesivas citas en castellano de esta obra.

${ }^{3}$ Retomando la perspectiva arendtiana, en su estudio sobre La violencia nazi, Traverso advierte que ésta implica una convergencia de premisas materiales -la serialización de los mecanismos técnicos para matar desarrollados por el imperialismo (Arendt) y la expansión de los dispositivos de encierro (Foucault) - y de un plano ideológico -los estereotipos generados por el racismo y el antisemitismo-. "La convergencia entre ambos planos, uno material y otro ideológico, comienza a esbozarse durante la Gran Guerra, el auténtico laboratorio del siglo XX, para hallar finalmente su síntesis en el nacionalsocialismo" (La violencia nazi. Una genealogía europea. Trad. de Beatriz Horrac y Martín Dupaus. Buenos Aires: FCE, 2003, p. 28).

4 BERNSTEIN, Richard. Hannah Arendt and the Jewish Question. Cambridge: Polity Press and Blackwell Publishers, 1996, p. 77. Véanse también otras referencias al legado ilustrado, pp. 17, 18, 52, 85. 180. La traducción me pertenece en esta y en las sucesivas citas en castellano de esta obra.

${ }^{5}$ En Hannah Arendt and the Jewish Question encontramos una referencia al Romanticismo alemán cuando se aborda el texto sobre Rahel (p. 18). Luego aparece una mención en relación con el caso Eichmann a "la falsa idea romántica" (p. 95) de que los judíos se podrían haber rebelado contra sus perpetradores y una última discusión sobre la presunta "iresponsabilidad romántica” (p. 112) de Arendt en su análisis del sionismo.
} 
Detenernos en el examen en las modernas corrientes intelectuales de la Ilustración y del Romanticismo, aspecto poco atendido en los estudios sobre el imperialismo y el totalitarismo, nos permitirá poner en evidencia que en Los orígenes del totalitarismo y en sus textos precedentes sobre la cuestión judía, Arendt emprende una crítica radical de la época moderna y de la tradición liberal, que luego será retomada y profundizada en su libro sobre la vida activa ${ }^{6}$. Buscaremos así esclarecer el camino que conduce a la sentencia arendtiana acerca del "final del humanismo" formulada en enero de 1956 en su Diario Filosófico ${ }^{7}$ y que constituye una de las inquietudes fundamentales que recorre La condición bumana. Sostenemos que este diagnóstico hunde sus raíces en su análisis de la modernidad elaborado en su libro sobre el totalitarismo y en particularmente en su posicionamiento crítico respecto de la Ilustración y el Romanticismo en relación con el antisemitismo y el pensamiento racial respectivamente. De modo que esta indagación resultará esclarecedora de la obra de Arendt y más precisamente de los puentes entre su indagación sobre el totalitarismo y sobre la vida activa, a la vez que respecto de su mirada de la modernidad y su rol en los acontecimientos políticos del siglo pasado.

\section{LA ILUSTRACIÓN Y LOS OTROS. EL CASO DEL ANTISEMITISMO}

En 1932 cuando en Alemania cobraba fuerza el nazismo y avanzaban sus políticas y prácticas antisemitas, Arendt publica "La Ilustración y la cuestión judía” en la Zeitscbrift für die Gescbichte der Juden in Deutschland ${ }^{8}$. Este texto explora las raíces del antisemitismo moderno,

\footnotetext{
${ }^{6}$ La condición humana radicaliza la crítica arendtiana de la modernidad inscribiéndola en el surgimiento de la tradición del pensamiento occidental con los griegos. De manera que no se trata sólo de examinar la época moderna sino también el pensamiento occidental en general. Al respecto véase el texto de Villa: "Totalitarianism, Modernity, Tradition" (en Politics, Philosophy, Terror. Essays on the Thought of Hannah Arendt. New Jersey: Princeton University Press, 1999, pp. 180-203).

7 "La naturaleza humana está descubierta en el animal laborans; eso es el final del humanismo [das Ende des Humanismus]. Éste ha alcanzado su meta [Ziel]" (ARENDT, Hannah. Denktagebuch 1950 bis 1973. Band I. LUDZ, Ursula y NORDMANN, Ingeborg (eds.). Münich: Piper, 2002, p. 558, XXI, 84. Traducción castellana: Diario filosófico 1950-1973. Trad. de Raul Gabás. Barcelona: Herder, 2006, p. 541, XXI, 84).

8 ARENDT, Hannah. "La Ilustración y la cuestión judía". En La tradición oculta. Trad. de R. S. Carbó y V. Gómez Ibañez. Buenos Aires: Paidós, 2004, pp. 109-127. Seguimos esta traducción remitiendo cuando es necesario al original en inglés. El ensayo se encuentra en la compilación La tradición oculta que es una traducción de la reedición de Sechs Essays [1948], el primer libro de Arendt publicado en Alemania, con la incorporación de algunos ensayos adicionales. La ciertamente arbitraria edición de las obras de Arendt, ha hecho que este primer libro que publicó después de la guerra en Alemania, haya sido reeditado después de su muerte bajo el título Die verborgene Tradition: Acht Essay (1978). En esta edición se excluyó el ensayo "Was ist Existez Philosophie?" que formaba parte del libro original, mientras que los restantes ensayos junto con la dedicatoria a Karl Jaspers se mantuvieron, y se incorporaron además otros dos ensayos: "Aufklärung und Judenfrage" y "Der Zionismus aus heutiger Sicht". El libro volvió a editar en el 2000 con el título ligeramente modificado Die verborgene Tradition: Essays y posteriormente fue traducido al español en la edición ya mencionada. El ensayo "The Enlightenment and the Jewish Question" también se encuentra publicado en ARENDT, Hannah. The Jewish Writings. KOHN, Jerome y FELDMAN Ron H. (eds.). New York: Schoken Books, 2007, pp. 9-19. El editor Jerome Kohn ha decidido reunir en compilaciones temáticas escritos publicados y no publicados en vida por Arendt. Lamentablemente no hay un criterio de edición unificado de la obra de Arendt entre el editor norteamericano Jerome Kohn y las editoras alemanas Ursula Ludz, Ingeborg Nordmann y Marie Luise Knott, a lo que se suma para complejizar la situación, la diversidad de editoriales intervinientes tanto en Estados Unidos (Harcourt Brace, University of Chicago Press, Viking y Schoken
} 
remontándose al movimiento de la Ilustración y especialmente a dos figuras destacadas de la cultura alemana de mediados y fines del siglo XVIII: Gotthold Ephraim Lessing y Johann Gottfried Herder. Podría resultar llamativo que bajo ese título Arendt incluyera también a Herder, que constituye uno de los críticos pioneros de la Ilustración y, como ella misma advierte, "cuya influencia en el Romanticismo será grande y decisiva". A pesar de cierto viraje y distancia de Herder respecto de la Ilustración, como veremos, comparte un horizonte de época que se manifiesta fundamentalmente en el modo de consideración de los otros y de lo diverso respecto de la cultura europea dominante.

Este camino será profundizado por Arendt en su libro Los orígenes del totalitarismo [1951], donde retoma ciertas ideas de Lessing y de Herder que, a pesar de sus buenas intenciones, desempeñaron un papel paradójico y finalmente nocivo para el posicionamiento social de los judíos. En el marco del humanismo ilustrado, Lessing entiende que por pertenecer a un pueblo despreciado y oprimido, los judíos constituían un modelo más puro de humanidad, y exaltó en consecuencia el carácter excepcional de los judíos mostrando el papel destacado que desempeñaban en la cultura. La exitosa obra de Lessing, Nathan el sabio, mostraba precisamente cómo el judío Nathan se destacaba resolviendo situaciones sociales complejas y lograba a través del diálogo salvar diferencias con representantes de otros credos -el Islam y el Cristianismo-. La clave para la integración de los judíos en la sociedad ilustrada, era que éstos se sometieran a un proceso integral de educación y formación (Bildung). De esta manera, la problemática judía era desplazada del plano político, presentándose como una cuestión de educación y cultura. En el siglo XVIII, mientras los judíos franceses comenzaban a disfrutar de la emancipación política y los judíos alemanes todavía esperaban por ella, en el plano social los judíos sólo eran asimilados y aceptados cuando se destacaban por su formación y sus aportes a la cultura. Así, "para la mentalidad ilustrada el propósito de emancipar a los judíos era el de proporcionarles los derechos humanos que disfrutaban los no judíos y «mejorar» su suerte borrando la historia que los había determinado"10.

Por su parte, para Herder los judíos encarnaban "nuevos especímenes de la humanidad", que al mismo tiempo que muestran la diversidad de manifestaciones culturales, "constituyen un ejemplo de posible intimidad entre todos los tipos de humanidad" 11 . Herder consideraba que la particular situación de los judíos cultos, los hacía más libres de prejuicios y también "propuso la

Books) como en Alemania (Piper y Suhrkamp). Las traducciones al castellano reproducen las ediciones anglosajonas o alemanas sin la debida explicación ni aclaración correspondiente. Para una somera reconstrucción de la historia de la edición de las obras de Arendt después de su muerte en el ámbito anglosajón y en el europeo, remitimos a la introducción de Ursula Ludz al capítulo "Werk und Werkgruppen" del libro editado por Wolfgang Heuer, Bernd Heiter y Stefanie Rosenmüller, Arendt Handbuch. Leben, Werk, Wirkung. Berlin: Metzler, 2011, pp. 11-20.

${ }_{9}$ Op. cit., p. 119.

${ }^{10}$ KOHN, Jerome. “Una vida judía: 1906-1975”. En: ARENDT, Hannah. Escritos judios. KOHN, Jerome y FELDMAN, Ron H. (eds.). Paidós: Madrid, 2009, p. 18.

11 ARENDT, Hannah. The Origins of Totalitarianism. New York: Harvest Books, 1979, p. 56. Traducción castellana: Los origenes del totalitarismo. Trad. de Guillermo Solana. Madrid: Taurus, 1999, p. 108. 
educación como verdadero camino para la emancipación de los judíos del judaísmo"12. Quisiéramos destacar que los judíos debían emanciparse del judaísmo a través de la cultura y la educación para ser considerados seres dignos de derechos, es decir, debían renunciar a su historia y su singularidad para ser aceptados como seres humanos genéricos en la sociedad. En "La Ilustración y la cuestión judía", Arendt cita las siguientes palabras de Herder: "Vencidos los viejos prejuicios nacionales; abandonadas las costumbres que no encajan con nuestra época ni con nuestras circunstancias, ni siquiera con nuestro clima, los judíos ya no son esclavos [...] sino gente integrada en los pueblos cultos $[\ldots]$ que trabaja en la construcción de la ciencia, de la cultura del género humano"13. Arendt encuentra dos problemas nodales en este abordaje de la cuestión judía: una imposibilidad de aceptar lo otro, lo distinto, por un lado, y una idea de humanidad o ser humano que bajo su apariencia de generalidad encubre la norma del modo de ser del hombre -varón ${ }^{14}-$ de la cultura europea dominante.

A la vez, la política de asimilación, tanto para los ilustrados como para los propios judíos, se basaba en la ilusión de que la integración se llevaría a cabo a través de la formación integral de la personalidad y del acceso a la cultura (Bildung $)^{15}$, desestimándose la dimensión política del problema. Al no detentar "un verdadero anclaje político" las medidas de integración del judaísmo "resultaban muy frágiles" ${ }^{16}$. Si los judíos querían asimilarse debían renunciar a su identidad judía, pero al mismo tiempo, era éste origen judío el que les abría las puertas para ser aceptados en los estrechos círculos sociales como judíos excepcionales. De esta forma, al tener que relegar públicamente su religión y sus costumbres, los judíos se sentían extraños al pueblo del que procedían, pero al ser reconocidos como judíos de excepción, su origen judío permanecía como algo que no permitía su plena asimilación social. Esta posición ambivalente que consistía en "pretender 'ser un hombre en la calle y un judío en casa $^{17}[\ldots]$ determinó un sentimiento de ser diferente de los demás hombres en la calle porque era judío y una diferencia respecto de los demás judíos en casa por no ser 'judío

\footnotetext{
12 Op. cit., p. 58. Traducción castellana, p. 109.

13 ARENDT, Hannah. "La Ilustración y la cuestión judía”. En La tradición oculta, p. 126. Arendt cita también estas palabras de Herder en The Origins of Totalitarianism, p. 58. La cita proviene de HERDER, J. G. "Über die politische Bekehrung der Juden”. En: Adrastea und das 18. Jabrhundert, 1801-03.

${ }^{14}$ En su artículo "Organized Guilt and Universal Responsability" publicado en 1945 en Jewish Frontier Arendt realiza un análisis de la figura del "paterfamilias" erigido como núcleo organizativo social y político en la época moderna y cuyas consecuencias se evidencian en el nazismo, extendiéndose hasta nuestros días. Véase: ARENDT, Hannah. Essays in Understanding 1930-1950. Formation, Exile, and Totalitarianism. KOHN, Jerome (ed.). New York: Schocken Books, 1994, pp. 121-132. En el apartado "La alianza temporal entre el populacho [mob] y la élite" del libro sobre el totalitarismo se analiza el papel del "hombre de familia [family men]" (The Origins of Totalitarianism, p. 338) en las SS de Himmler.

15 En Herder la noción de Bildung adquiere el sentido de "ascenso a la humanidad", de manera que, "de acuerdo a la idea herderiana de formación, lo específicamente humano en el hombre es el resultado de un logro, de una manera particular de darle forma a las disposiciones y capacidades con las que un individuo humano está dotado naturalmente" (KARCZMARCZYK, Pedro. Gadamer: aplicación y comprensión. La Plata: Edulp, 2007, p. 68).

16 TRAVERSO, Enzo. La historia desgarrada. Ensayo sobre Auschwitzy los intelectuales. Trad. de David Chiner. Barcelona: Herder, 2001, p. 83.

${ }_{17}$ Así reza el poema hebreo de Judah Leib Gordon, Hakitzah ami, 1863, citado por Arendt en The Origins of Totalitarianism, p. 65, nota 27.
} 
ordinario'."18. Para ser asimilados, los judíos debían mostrar sus cualidades excepcionales en materia intelectual, y consecuentemente permanecían como extraños frente a su pueblo.

Difícilmente pueda sobreestimarse el desastroso efecto de esta exagerada buena voluntad hacia los judíos cultos y recientemente occidentalizados y el impacto que tuvo en su posición social y psicológica. No sólo tuvieron que enfrentarse éstos con la desmoralizante exigencia de ser excepciones respecto de su propio pueblo [...] se esperaba de ellos, además, que se convirtieran en especímenes excepcionales de la Humanidad. Y [...] esto, y no la conversión de Heine, constituía la verdadera 'tarjeta de admisión' en la sociedad culta europea. ${ }^{19}$

La asimilación significaba, entonces, mostrar un carácter excepcional respecto de su propio pueblo y al mismo tiempo, la renuncia a los hábitos y costumbres judías, en pos de volverse en un ser un humano como cualquier otro. La vía de la asimilación, como una forma de procurar la siempre tan anhelada integración social, exigía que los judíos se vuelvan indistinguibles del resto de la sociedad. Arendt critica a la Ilustración porque bajo sus pretensiones de reconocer a los seres humanos en general se oculta una imposibilidad de reconocer a los judíos y a otras culturas en su especificidad. Los ilustrados nunca aceptaron a los judíos en tanto que judíos sino sólo bajo la condición de que dejaran de serlo. Esta crítica a la incapacidad de aceptar las diferencias, no afecta sólo a la Ilustración sino también al modo de funcionamiento del Estado nación ${ }^{20}$ moderno y a la tradición más amplia del pensamiento político liberal en la que se inscribe. Esta tradición con su unidad de análisis en el individuo y su búsqueda de lo general por sobre las singularidades, desemboca consecuentemente en una animosidad hacia las diferencias culturales. En este sentido, Bernstein advierte respecto "de la insatisfacción de Arendt con la tradición liberal clásica. El lado oscuro de esta tradición es su intolerancia y hostilidad para reconocer a los judíos como un pueblo particular y no sólo como una colección de individuos abstractos con una religión privada"21. La cuestión judía pone así de manifiesto la incompetencia de la tradición liberal moderna no sólo para reconocer a los judíos sino para reconocer a las minorías en general22. Y esto se volverá una problemática fundamental a lo largo de todo el siglo XX -con un momento álgido en el totalitarismo nazi- que prosigue hasta nuestros días 23.

\footnotetext{
18 ARENDT, Hannah. The Origins of Totalitarianism, p. 65. Traducción castellana, p. 117.

${ }^{19}$ Op cit., pp. 58-59. Traducción castellana, pp. 109-110.

20 Respecto de la crítica de Arendt al Estado nación véase: DI PEGO, Anabella. "El imperialismo y la decadencia del Estado nación". En: La modernidad en cuestión. Totalitarismo y sociedad de masas en Hannah Arendt. La Plata: Edulp, 2015, pp. 91-141.

21 BERNSTEIN, Richard. Hannah Arendt and the Jewish Question. Cambridge: Polity Press and Blackwell Publishers, 1996, p. 26.

22 "A menudo se ha dicho que los judíos son la minoría por excelencia porque no tienen una madre patria [motherland], una afirmación que es correcta, al menos en la medida en que era la única minoría existente que podía ser completamente despolitizada, pues carecía del único factor político que, con independencia de todas las definiciones legisladas, inevitablemente politiza a una minoría: la madre patria [motherland]", ARENDT, Hannah. "The Minority Question [1940]". En: Jewish Writings, p. 126. Hemos corregido la traducción castellana reemplazando "patria" por "madre patria" para traducir "motherland" (Escritos judíos, p. 200).

${ }^{23}$ Para un abordaje contemporáneo de la relevancia de la perspectiva arendtiana para el problema del derecho de las minorías, véase BENHABIB, Seyla. “«El derecho a tener derechos» Hannah Arendt y las
} 
Incluso aquellos ilustrados que bregaban por la emancipación política de los judíos "exigían la asimilación, es decir, la adecuación y la recepción por parte de la sociedad, lo que era considerado o bien condición preliminar de la emancipación judía o su consecuencia automática" ${ }^{24}$. La emancipación política y la asimilación social constituían dos caras inseparables del tratamiento de la cuestión judía por parte de la Ilustración. En 1952, en una carta a Jaspers en relación con la situación de los judíos en el siglo XVIII, Arendt manifiesta: “Todavía creo hoy que bajo las condiciones de la asimilación social y la emancipación política los judíos no podrían 'vivir' [...] Bajo estas condiciones especiales, la Ilustración [Enlightenment] desempeñó un rol sumamente cuestionable"25.

Los judíos que adhirieron a la Ilustración también desempeñaron un papel objetable. Moses Mendelssohn creía que a través de la educación, los judíos podían ser asimilados a la sociedad sin advertir los riesgos que ello implicaba, puesto que "asimilarse" suponía absorber e incorporarse a la sociedad que rechazaba a los judíos y esto implicaba, asimilarse también al antisemitismo. Enzo Traverso advierte que esto dio lugar entre los judíos advenedizos “a la autonegación, que podía expresarse entonces bajo la forma muy conocida de la autofobia judía (jüdischer Selbsthass)"26. Estas consecuencias de la asimilación se hicieron evidentes en la siguiente generación de judíos asimilados, quienes rechazaron explícitamente la religión y la historia de su pueblo en pos de despojarse de todas las singularidades para poder ser aceptados como seres humanos. El problema es que nadie puede autorrealizarse simplemente en tanto ser humano, sino en el seno de una cultura y de una tradición particular. De algún modo, los judíos asimilados sabían esto y por eso empuñaron con tanto ímpetu la cultura ilustrada que había desplazado a sus antiguas creencias.

La segunda generación de asimilados (representada por David Friedländer, el discípulo de Mendelssohn) sigue aferrándose a la tesis ilustrada de la corrupción histórica. Partiendo de esta base tan idónea para sus aspiraciones, esta generación, que, a diferencia de Mendelssohn, ha roto sus vínculos con la religión, trata por todos los medios de hacerse un hueco en la sociedad. Se identifica hasta tal punto con la obcecación de la Ilustración, para la que los judíos no son más que gente oprimida, que renuncia a su propia historia y considera que todo lo suyo es tan sólo un obstáculo para su integración real en la sociedad, para su autorrealización como seres humanos. ${ }^{27}$

La asimilación en tanto conlleva a la indistinción y a la igualación de los judíos con el resto de la sociedad, debe ser comprendida asimismo en el marco de la centralidad que la noción de igualdad desempeñó en el ideario ilustrado moderno. Mientras que la igualdad resulta sumamente legítima en el ámbito político, puesto que implica un reconocimiento en el plano formal y legal; la

contradicciones del Estado-nación". En El derecho de los otros. Extranjeros, residentes y ciudadanos. Trad. de Gabriel Zadunaisky. Barcelona: Gedisa, 2005, pp. 45-60.

24 ARENDT, Hannah. The Origins of Totalitarianism, p. 56. Traducción castellana, p. 108.

25 ARENDT, Hannah y JASPERS, Karl. Hannah Arendt and Karl Jaspers. Correspondence 1926-1969. Trad. de Robert and Rita Kimber. New York: Harvest Book, 1993, pp. 198-199.

26 TRAVERSO, Los judios y Alemania. Ensayos sobre la "simbiosis judio-alemana”.Trad. de Isabel Sancho García. Valencia: Pre-textos, 2005, p. 188.

27 ARENDT, Hannah. "La Ilustración y la cuestión judía". En: La tradición oculta, pp 116-117. El destacado me pertenece. 
transposición de la igualdad desde el ámbito político al social genera consecuencias peligrosas. En el ámbito social, la igualdad conduce a la homogeneidad y a la normalización, que terminan poniendo en cuestión cualquier tipo de diferenciación social. Así, comenzamos a vislumbrar los alcances de la crítica de Arendt al legado político de la modernidad plasmado en el ideario de la Revolución francesa con su vindicación de la igualdad.

La igualdad de condición, aunque es ciertamente un requerimiento básico de la justicia, figura, sin embargo, entre los mayores y más inciertos riesgos de la humanidad moderna. Cuanto más iguales son las condiciones, menos explicaciones hay para las diferencias que existen en la gente; y así más desiguales se tornan los individuos y los grupos [...] Allí donde la igualdad se torna un hecho mundano en sí misma [...] hay un noventa y nueve por ciento de probabilidades de que será confundida con una cualidad innata de cada individuo que es "normal" si es como todos los demás y "anormal" si resulta ser diferente. Esta perversión de la igualdad, de un concepto político a un concepto social, es aún mucho más peligrosa cuando una sociedad no deja el más pequeño espacio para los grupos e individuos especiales, porque entonces sus diferencias se tornan aún más conspicuas. ${ }^{28}$

Los efectos de la igualdad resultaron paradójicos, porque allí donde las minorías son reconocidas como iguales, la sociedad que no acepta esta condición reacciona con virulenta discriminación. De este modo, al bregar por la igualdad se culmina generando mayor hostilidad respecto de las diferencias en el ámbito social. "Como la igualdad exige que yo reconozca a cada individuo como igual, el conflicto entre grupos diferentes que por razones propias sienten repugnancia a otorgarse entre sí esta igualdad, adopta formas tan crueles”29. En este contexto, cuanto más se procuraba igualar a los judíos, más reaccionaba la sociedad contra ese grupo que veía como irreductiblemente diferente a pesar de sus esfuerzos por no distinguirse. "Esta nueva conciencia condujo a un resentimiento social contra los judíos y al mismo tiempo a una atracción peculiar hacia ellos" 30 , por constituir lo diferente en una sociedad cada vez más homogénea. En este sentido, la segregación de los judíos procedió tanto de quienes los denigraban como de quienes exaltaban sus diferencias, puesto que el hecho de ser concebidos por los ilustrados como "nuevos especímenes de la humanidad" los situaba en una posición excepcional que puede fácilmente trocar en estigmatización. "La formación de un tipo judío fue debida tanto a la discriminación especial como al favor especial" 31.

De este modo, la excepcionalidad que en el siglo XVIII les había abierto a los judíos las puertas de la sociedad, en el siglo siguiente comenzó a mostrarlos como lo distinto y lo exótico, como aquello que difería de la norma y por tanto debía ser explicado en términos misteriosos o secretos. Los ilustrados, sin proponérselo, habían contribuido al desarrollo de tendencias antisemitas, al caracterizar a los judíos como inherentemente distintos por sus potencialidades intelectuales. Sin embargo, la discriminación social de los judíos en el siglo XIX no "causó gran daño político" debido a la persistencia de la diferenciación de clases en cuyo marco "podía soportar

28 ARENDT, Hannah. The Origins of Totalitarianism, p. 54. Traducción castellana, p. 105.

${ }^{29}$ Op. cit., p. 55. Traducción castellana, p. 106.

${ }^{30}$ Ibíd.

${ }^{31}$ Ibíd. 
la sociedad que los judíos se establecieran por sí mismos como grupo especial”32. La situación se agravará con el surgimiento de las masas hacia finales del siglo XIX y de los movimientos de masas en el siglo pasado, en donde se expande la indistinción social y convergen el antisemitismo social y el político 33 .

\begin{abstract}
Dentro del marco de esta sociedad, la judeidad, tras haber sido tergiversada en cualidad psicológica, podía ser fácilmente pervertida en vicio. La genuina tolerancia y la curiosidad por todo lo humano de la Ilustración fueron reemplazadas por una morbosa concupiscencia por lo exótico, por lo anormal y diferente como tal. Varios tipos en la sociedad, uno después de otro, representaban lo exótico, lo anómalo, lo diferente, pero ninguno de ellos estaba ni siquiera mínimamente conectado con las cuestiones políticas. De esta forma únicamente el papel de los judíos en esta sociedad decadente podía asumir una estatura que trascendería los estrechos límites de un asunto de sociedad. ${ }^{34}$
\end{abstract}

En el transcurso del siglo XIX, el judaísmo, entendido como un conjunto de creencias vinculadas a una historia y a una tradición compartidas, fue relegado y reducido a la judeidad que remite a "un dato existencial ineluctable y transforma lo que era considerado como una identidad común a otros en un rasgo psicológico individual”35. Así, la judeidad comenzó a ser vista como un atributo de nacimiento del que ya no era posible escapar mediante la conversión. La judeidad, entonces, se convirtió en un estigma, que hacía a los judíos socialmente "culpables" no por haber cometido delito alguno sino por el mero de hecho ser judíos. De este modo, la judeidad había dejado de ser un delito que podía ser castigado dentro de la normativa vigente y se transforma en un vicio social frente al cual, en la medida en que el ser judío se ha tornado una categoría ontológica irreductible, solo queda la "solución" de la eliminación. Hacia finales del siglo XIX, el antisemitismo se tornó un fenómeno social mordaz y extendido, al tiempo que adquirió relevancia como elemento de movilización política. Por eso, Arendt manifiesta que "el tipo de antisemitismo nazi tenía sus raíces en estas condiciones sociales tanto como en condiciones políticas" 36 . Esta "mezcla insoluble de motivos políticos y de elementos sociales"37 explica cómo fue posible que el antisemitismo llegara a ser el foco de una ideología política, que en el siglo XX mostró su potencialidad devastadora.

\title{
EL ROMANTICISMO ALEMÁN Y EL PENSAMIENTO RACIAL
}

\footnotetext{
32 Ibíd.

${ }^{33} \mathrm{El}$ antisemitismo social puede conducir a diversas formas de discriminación y a feroces pogromos, pero no a un exterminio masivo por su falta de organización política; mientras que el antisemitismo político es capaz de conducir a legislaciones antisemitas, que pueden implicar desnaturalizaciones, expulsiones y persecuciones, pero sólo puede dar lugar a un exterminio masivo cuando tiene un profundo asidero en la discriminación social extendida. De esta manera, la letalidad del antisemitismo nazi se encuentra relacionada con esta confluencia del antisemitismo político y del social, o más precisamente, con el surgimiento de un antisemitismo político sustentado en la discriminación social a los judíos, que se había difundido en la sociedad, ofreciendo amplias bases sociales susceptibles de ser movilizadas.

34 Op. cit., pp. 67-68. Traducción castellana, p. 120.

35 BACCI, Claudia. “¿Puede lo personal ser político?”. En: Deus Mortalis. Cuaderno de Filosofía Política. Buenos Aires: n. 7, 2008, p. 183.

${ }^{36}$ ARENDT, Hannah. The Origins of Totalitarianism, p. 87. Traducción castellana, p. 141.

37 Ibíd.
} 
En la segunda parte de Los origenes del totalitarismo, Arendt dedica algunas páginas al Romanticismo en su versión alemana ${ }^{38}$. Una aproximación a su abordaje del Romanticismo, nos permitirá esclarecer los aportes de esta corriente de pensamiento a la emergencia del totalitarismo, así como también el posicionamiento arendtiano respecto de la modernidad. En los estudios sobre Arendt pueden encontrarse algunas referencias al Romanticismo en relación con el salón de Rahel Varnhagen ${ }^{39}$, con la exaltación romántica de la intimidad frente al ascenso de lo social en La condición bumana ${ }^{40}$ y por último, con la inscripción de Heidegger en el Romanticismo ${ }^{41}$. Sin embargo, no ha sido mayormente explorado el papel del Romanticismo en Los orígenes del totalitarismo. Por eso, hemos considerado oportuno revisar someramente esta cuestión con el objeto de mostrar que el Romanticismo es una preocupación que recorre su obra y que resulta nodal para comprender el derrotero de la modernidad.

Comenzaremos reconstruyendo someramente su análisis del Romanticismo presente en su libro sobre Rahel Varnhagen ${ }^{42}$ para luego examinar el modo en que aborda el tema en la segunda parte de su libro sobre el totalitarismo, dedicada al imperialismo. En 1929, Arendt emprende su estudio de la vida de Rahel Varnhagen (1771-1833) en el marco de su segunda disertación (Habilitationschrift) para acceder a la carrera universitaria alemana ${ }^{43}$. El libro se publica recién en 1958 por iniciativa del Instituto Leo Baeck traducido al inglés por Richard y Clara Winston y al año siguiente aparece también por primera vez en alemán en Munich por la editorial Piper. En el prólogo, Arendt señala que el manuscrito del libro, a excepción de los dos últimos capítulos escritos en el verano de 1938 en su exilio en París-, se encontraba terminado en 1933 cuando tuvo que emigrar de Alemania ${ }^{44}$ y una copia se conserva en el legado de Jaspers en el archivo de literatura alemana de Marbach (Deutsche Literaturarchiv Marbach).

\footnotetext{
38 Op. cit., pp. 167-1700. Traducción castellana, pp. 231-234.

$39 \mathrm{Al}$ respecto véase: ; CANOVAN, Margaret. Hannah Arendt. A Reinterpretation of her Political Thought, p. 9; y BENHABIB, Seyla. The Reluctant Modernism of Hannah Arendt, pp. 11, 12 y 191. En el libro de Benhabib se aborda el Romanticismo en relación con el caso de Rahel Varnhagen pero no hay ninguna referencia al tratamiento del mismo en su libro sobre el totalitarismo.

40 Véase: SWIFT, Simon. Hannah Arendt, London, Routledge, 2009, p. 22 y 40; VILLA, Dana. Arendt and Heidegger. The Fate of the Political. New Jersey: Princeton University Press, 1996, p. 140.

${ }^{41}$ Remitimos a: KRISTEVA, Julia. El genio femenino. Hannah Arendt. Trad. de Jorge Piatogorsky. Buenos Aires: Paidós, 2003, p. 134; YOUNG-BRUEHL, Elisabeth. Hannah Arendt. Trad. de Manuel Lloris Valdés. Valencia: Alfons el magnànim, 1993, p. 284; VILLA, Dana. Arendt and Heidegger. The Fate of the Political, p. 232. ${ }^{42}$ Seyla Benhabib examina las principales líneas argumentativas sobre Rahel Varnhagen en su texto "La paria y su sombra: la biografía de Hannah Arendt sobre Rahel Varnhagen”, en BIRULES, Fina (comp.). Hannah Arendt. El orgullo de pensar. Trad. de Javier Calvo Perales. Barcelona: Gedisa, 2000, pp. 97-115. Por su parte, Rita Novo (Hannah Arendt. El relato sobre Rabel Varnhagen. Mar del Plata: Eudem, 2011) ha analizado el relato sobre la vida de Rahel en sus implicancias respecto de la posterior concepción arendtiana de la narración. Sin embargo, entendemos que en esta instancia Arendt todavía no había desplegado las particularidades de su abordaje de la narración, por lo que el libro sobre Rahel resulta más relevante en cuanto a sus análisis de la cuestión judía, de la asimilación, de la Ilustración y del Romanticismo.

${ }^{43}$ Su primera disertación se había titulado El concepto de amor en San Agustín.

${ }^{44}$ ARENDT, Hannah. Raher Varnhagen. Vida de una mujer judía. Trad. de Daniel Najmías. Barcelona: Lumen, 2000, p. 11.
} 
En el intercambio epistolar entre Arendt y Jaspers se aborda la cuestión de la publicación del libro. En una carta del 23 de agosto de 1952, Jaspers le presenta sus reservas respecto de que el libro sea publicado tal cual se encontraba y le propone algunas líneas para la reelaboración del trabajo ${ }^{45}$. El 7 de septiembre del mismo año, Arendt le responde a Jaspers que aunque comparte algunas de estas reservas respecto del libro, principalmente debido a que no está presente su posterior distinción entre el antisemitismo social y el político, considera que la argumentación principal sigue siendo relevante tanto en lo que respecta a las críticas a la asimilación y a la emancipación política de los judíos, como en lo referido al "papel altamente cuestionable" que desempeñó la Ilustración en la cuestión judía ${ }^{46}$. Nuevamente encontramos una sintonía entre la Ilustración y el Romanticismo en lo que respecta a la asimilación y del tratamiento del asunto de los judíos. El libro sobre Rahel Varnhagen constituye una indagación en torno del Romanticismo y por eso el subtítulo en alemán es Lebensgeschichte einer deutschen Jüdin aus der Romantik, lo que se desdibuja en el subtítulo en inglés The Life of a Jewish Woman, y en la respectiva traducción al castellano, que sólo recogen la condición de Rahel de mujer ${ }^{47}$ y de judía, pero sin hacer referencia a su origen alemán y a su procedencia de la época del Romanticismo. En torno de esa conjunción de ser judía y alemana durante el Romanticismo se concentra precisamente el análisis arendtiano. Aunque el Romanticismo se presente como una reacción de cara a la Ilustración, Arendt muestra que ambos movimientos comparten un modo de concebir la asimilación y la integración social que no deja resquicios para los judíos ni para otras manifestaciones culturales diversas ${ }^{48}$.

Asimismo, a través del caso de Rahel Varnhagen, Arendt cuestiona la exaltación romántica de la interioridad o del propio mundo interior por la consecuente desvinculación del pensamiento respecto del mundo compartido. De este modo, "el pensamiento funciona como una especie de magia ilustrada que permite reemplazar, crear y anticipar la experiencia, el mundo, los hombres y la sociedad"49. Arendt encuentra en el Romanticismo una tendencia que en consonancia con la tradición filosófica tiende a consagrar la superioridad del pensamiento y con ello a independizarlo del mundo ${ }^{50}$. Acá reside la profundidad de su crítica que supone no sólo repensar la vita activa sino también su relación con el pensamiento, desafiando las concepciones que consideran a este último autosuficiente.

\footnotetext{
45 ARENDT, Hannah y JASPERS, Karl. Hannah Arendt and Karl Jaspers. Correspondence 1926-1969, pp. $192-196$. 46 Op. cit., pp. 196-201.

${ }^{47}$ Benhabib ha analizado la especial relevancia de que Arendt señale que se trata de una mujer, mostrando los rasgos que hacen de los salones una esfera pública femenina (The Reluctant Modernism of Hannah Arendt, pp. 1422).

${ }^{48}$ Canovan considera que "Arendt creía que el totalitarismo había sido posible por el colapso de la civilización humanista e ilustrada” (Hannah Arendt. A Reinterpretation of her Political Thought, p. 21). Así Canovan asocia el Romanticismo con el nazismo (por su rechazo del capitalismo y de la racionalidad occidental moderna con sus instituciones políticas) oponiéndolos a cierta visión ilustrada, que queda eximida de responsabilidad frente al totalitarismo. Por nuestra parte, procuramos mostrar que a pesar de sus diferencias, la Ilustración y el Romanticismo comparten una concepción de los otros individuos y de los pueblos y culturas minoritarias que impregna a las instituciones políticas liberales haciendo posible la expansión del antisemitismo y del racismo. ${ }^{49}$ ARENDT, Hannah. Rahel V arnhagen. Vida de una mujer judia, p. 28.

${ }^{50}$ CANOVAN, Margaret. Hannah Arendt. A Reinterpretation of her Political Thought, p. 9.
} 
Este proceso de desvinculación del pensamiento del mundo, tiene implicancias en la propia vida activa, dando lugar al fenómeno posteriormente denominado "alienación del mundo" (world alienation), característico de la condición humana en la época moderna ${ }^{51}$ y expresado paradigmáticamente en la filosofía de Descartes. La vida de Rahel Varnhagen permite entender esta modalidad de alienación en su carácter histórico y en sus implicancias prácticas y concretas en la vida. No se trata de una alienación respecto de sí mismo sino de un extrañamiento del mundo común con graves y peligrosas consecuencias políticas. Lo que aqueja a Rahel Varnhagen es expresión, según sus palabras, de que "el mundo fermenta" 52 , de que se erosiona ese mundo compartido de los salones berlineses de comienzos del siglo XIX.

A diferencia del sentido tradicional de la alienación del ser humano de su modo de ser propio (self alienation), la alienación del mundo compartido implica recluirse en las certezas absolutas de la propia interioridad. La certeza del propio pensamiento se adquiere a través de la duda radical de nuestros sentidos y consecuentemente del mismo mundo y de los otros, y sólo una vez alcanzada la certeza indubitable del cogito resulta posible restablecer de manera derivada, a través de la bondad divina, la posibilidad de conocimiento del mundo exterior. Con este punto de partida moderno desde la certeza absoluta del propio pensamiento, surge el problema del solipsismo, que aunque sea superado implica que el mundo exterior tiene un carácter derivado del propio pensamiento.

Una de las más persistentes tendencias de la filosofía moderna de Descartes, y quizás su contribución más original a la filosofía, ha sido la exclusiva preocupación por el yo, diferenciado del alma, la persona o el hombre en general, [y el] intento de reducir todas las experiencias, tanto con el mundo como con otros seres humanos, a las propias del hombre consigo mismo [...] La alienación del mundo [world alienation], y no la alienación de sí mismo [self alienation] como creía Marx, ha sido la marca característica de la Época Moderna. ${ }^{53}$.

El Romanticismo con su concepción del sentimiento (Gefübh), de la individualidad (Individualität) y del genio (Genie), constituye en cierto modo la variante alemana del cambio de perspectiva iniciado en Francia por Descartes, y en este sentido ambas llevan consigo una consecuente huida del mundo hacia la propia interioridad ${ }^{54}$. A pesar de las diferencias entre estas corrientes, ambas terminan suscribiendo a un cierto subjetivismo aunque con diferentes matices por

\footnotetext{
51 Según Arendt, la época moderna (modern age) se inicia con la Reforma protestante en el siglo XVI, y se consolida durante el siglo siguiente con el impacto del descubrimiento de América y de la invención del telescopio. Estos tres acontecimientos se encuentran a la base de la doble alienación que caracteriza a la modernidad, la ya mencionada alienación del mundo (world alienation) y la alienación de la Tierra (earth alienation). Mientras que la primera se plasma en el desarrollo de la filosofía moderna a partir de Descartes, el segundo fenómeno se puede observar en el surgimiento de la ciencia moderna con Galileo. Véase: ARENDT, Hannah. The Human Condition. Chicago: Chicago University Press, 1998, pp. 248-289. Traducción castellana: La condición bumana, trad. de Ramón Gil Novales, Barcelona, Paidós, 2001, pp. 277-314.

52 ARENDT, Hannah. Rahel Varnhagen. Vida de una mujer judía, p. 166.

53 ARENDT, Hannah. The Human Condition, p. 254. Traducción castellana, p. 282.

${ }^{54}$ Véase al respecto el análisis de Benhabib sobre la "instrospección romántica" y la pérdida de mundo de Rahel Varnhagen, en The Reluctant Modernis of Hannab Arendt, pp. 11-12.
} 
lo que es posible referirse al "implacable individualismo del romanticismo" 55 o a un "subjetivismo romántico" ${ }^{56}$. Esto se encuentra presente en la filosofía de Heidegger y hace que no podamos sencillamente desestimar los pormenores de su proceder, puesto que "ese modo de comportarse tiene paralelos cabales en el romanticismo alemán" 57 . Por eso, Arendt asevera "Heidegger es de hecho (esperemos) el último romántico, una suerte de Friedrich Schlegel o Adam Müller de portentosas dotes" 58 . Nuevamente la comprensión de los acontecimientos del siglo XX, y de ahí la relevancia del caso de Heidegger, nos lleva a remontarnos a fenómenos propios de la época moderna, y en este caso, particularmente al Romanticismo alemán.

Hacia finales del siglo XVIII se produce el apogeo de los salones judíos en Berlín, entre ellos el de Rahel Varnhagen, seguido por su decadencia a comienzos del siglo siguiente. En 1806 con la entrada de Napoleón en Berlín, las reuniones en los salones judíos fueron disolviéndose ante la creciente reacción nacionalista y antisemita de los círculos aristocráticos, al tiempo que iban siendo reemplazadas por encuentros en las casas de la ascendente burguesía. Arendt advierte que este desplazamiento de los salones lejos de conducir a una ampliación de los círculos de reunión acentuó su exclusividad, dando lugar a la conformación de sociedades patrióticas secretas. Así mientras que en los salones judíos se mezclaban los aristócratas ilustrados con los intelectuales de clase media, en los nuevos espacios de reunión prevalecen los encumbrados funcionarios públicos y los hombres de negocios influyentes, cohesionados no sólo por afinidad sino fundamentalmente por la procedencia social y por la exclusión de quienes antes podían participar de los salones judíos.

Lo característico es que ahora [hacia 1809], junto con la rancia nobleza rural y los altos oficiales, tome la palabra justamente el funcionariado, un grupo que hasta entonces no había podido competir socialmente con los salones judíos. Sus reuniones llevan la clara impronta de las sociedades patrióticas secretas, y son, además -en consciente contraste con la indiscriminación del salón judío-, muy exclusivas. Esta nueva vida social, claramente politizada, no se da por satisfecha con ser simplemente un salón, y busca formas de cohesionar mejor a sus miembros [...] La Tischgesellschaft es, con unos sólidos estatutos, una asociación en toda regla. Numéricamente predomina la nobleza; el romanticismo marca el tono. Los estatutos excluyen a las mujeres, los franceses, los filisteos y los judíos. (RV: 167).

El romanticismo no es sólo una corriente que se expresa en terrenos culturales diversos sino una cosmovisión que impregna una época ${ }^{59}$ y "marca el tono" de las nuevas asociaciones "reemplazando la discusión y el libre examen racional por el misterio, el rito, la jerarquía”60. De este

55 ARENDT, Hannah. The Origins of Totalitarianism, p. 168. Traducción castellana, p. 232. Al respecto véase también el análisis de Young-Bruehl sobre "el individualismo romántico" (en Hannah Arendt, p. 285).

${ }^{56}$ VILLA, Dana. Arendt and Heidegger. The Fate of the Politica, p. 232.

57 ARENDT, Hannah. “¿Qué es la filosofía de la existencia?”. En Ensayos de comprensión 1930-1954. Trad. de Agustín Serrano de Haro. Madrid: Caparrós, 2005, p. 218, nota 4.

${ }^{58}$ Ibíd.

${ }^{59}$ LÖWY, Michel y SAYRE, Robert. Rebelión y melancolía. El romanticismo como contracorriente de la modernidad, trad. de Graciela Montes, Buenos Aires, Nueva Visión, 2008, p. 23.

60 Op. cit., p. 67. Aunque la argumentación del libro de Löwy y Sayre parece discurrir en abierta contraposición con el análisis de Arendt, puesto que ellos entienden al romanticismo como una contracorriente de la modernidad, sin embargo, cuando caracterizan específicamente al romanticismo en Alemania destacan su vinculación con la religión, principalmente con el pietismo luterano y con las "sectas 
modo el romanticismo, aporta ciertos rasgos identitarios, al tiempo que las diversas exclusiones, y especialmente la exclusión de las mujeres y de los judíos, resultan constitutivas de las nuevas asociaciones, con la consecuente misoginia y antisemitismo que esto conlleva.

En su libro sobre el totalitarismo, Arendt advierte que la marca característica de los intelectuales románticos no reside en un conjunto de opiniones sino en la formación de una "mentalidad general" entre los sectores cultos, en donde la personalidad y el genio se vuelven una forma de distinción social. En Alemania hacia comienzos del siglo XIX, la ascendente clase media mercantil se encuentra con el desprecio de la nobleza por los negocios y su renuencia a relacionarse con quienes se dedicaban a estas actividades. En este contexto, los individuos de la clase media procuran forjarse una "personalidad" a través de la formación (Bildung) para lograr cierto reconocimiento social. Esta situación es retratada por Johann Wolfgang von Goethe, en su clásica novela de formación (Bildungsroman) denominada Los años de aprendizaje de Wilhelm Meister, en donde el protagonista es educado por nobles en vistas de modelar una personalidad de la que carece debido a su origen social burgués.

De este modo, los intelectuales románticos alemanes en procura de reconocimiento frente a la nobleza, desarrollaron una "idolatría de la personalidad del individuo, cuya misma arbitrariedad se convierte en prueba de genio"61. La exaltación de la interioridad en la formación de la personalidad y de capacidad creativa del genio, por un lado, abonan a la mencionada tendencia hacia al subjetivismo, y por otro lado, en la medida en que son concebidas como capacidades innatas, sientan las bases para una diferenciación social que deriva en una peligrosa estigmatización social. A través del concepto de "personalidad innata" la ascendente burguesía hace referencia a cualidades naturales vinculadas a la noción de genio que se erigen en muestra de mayor grandeza que los títulos de nobleza susceptibles de ser otorgados y revocados de acuerdo a la determinación humana. Asimismo, la personalidad innata se volvió un rasgo distintivo que la burguesía utilizó para diferenciarse tanto de otros estratos sociales cuanto de otros pueblos considerados inferiores. "La burguesía alemana trataría de atribuir a otros pueblos todas las cualidades que la nobleza despreciaba como típicamente burguesas - primero a los franceses, más tarde a los ingleses y siempre a los judíos"62. De ahí que el culto a la personalidad innata culminara por estigmatizar a otros pueblos y fomentara no sólo el antisemitismo sino también la proliferación del pensamiento racial. "Fue la falta de una 'personalidad innata', la falta innata de tacto, la falta innata de

más o menos ocultas e iluminadas", lo que le otorga un particular carácter místico que "va a tener influencia directa sobre la Naturphilosophie del romanticismo, desde Schelling hasta Franz von Baader" (Ibíd.). En este sentido, es necesario aclarar que el análisis de Arendt se acota al denominado romanticismo alemán vinculado con los siguientes nombres: Herder, Schiller, Goethe, Schlegel, Müller, entre otros. Mientras que Löwy y Sayre (Op. cit., pp. 71-102) realizan una tipología que permite diferenciar y organizar la complejidad de las corrientes que conforman el romanticismo en diversos tipos: restitucionista, conservador, fascista, resignado, reformador, revolucionario y/o utópico.

61 ARENDT, Hannah. The Origins of Totalitarianism, p. 168. Traducción castellana, p. 232.

${ }^{62}$ Op. cit., p. 169. Traducción castellana, p. 233. 
productividad, la disposición innata para el comercio, lo que separó el comportamiento el hombre de negocios judío del de su colega medio"63.

En su artículo "La Ilustración y la cuestión judía", Arendt ya había establecido un íntimo vínculo entre el Romanticismo y el antisemitismo, refiriéndose al primero como "la tradición alemana que merece la mayor consideración en relación con la cuestión judía" ${ }^{4}$. Sin embargo, en la primera parte de Los origenes del totalitarismo abocada al antisemitismo, se pueden encontrar sólo un par de menciones esporádicas al Romanticismo y a los intelectuales románticos. Así, Arendt señala que los intelectuales románticos contribuyeron a que el conservadurismo llegara a constituir una ideología política en Alemania ${ }^{65}$ y junto con las tendencias antisemitas de esta ideología, ellos mismos se tornaron antisemitas ${ }^{66}$. Sin embargo, dadas estas escasas referencias, cabría preguntarnos si acaso Arendt no ha cambiado de opinión en relación con la importancia del Romanticismo para el antisemitismo.

En todo caso, esto deja entrever una modificación en la perspectiva de Arendt que vira desde un análisis filosófico de orientación idealista con primacía en las tradiciones de pensamiento en la década del treinta -el Romanticismo y la Ilustración-, hacia un análisis histórico-filosófico ${ }^{67}$ que recala y enfatiza en el papel de las prácticas económicas -el imperialismo- y sociales -el racismo- en la década siguiente. En este sentido, como ya hemos mencionado, Canovan enfatiza el plano de las prácticas por sobre el plano de las ideas entre los elementos que se encuentran a la base del totalitarismo. El problema es que Canovan parece dejarse llevar al extremo por esta aseveración y culmina soslayando el rol que las tradiciones intelectuales desempeñan en el libro de Arendt. Si bien es cierto que hacia la década del cuarenta cobran preeminencia las prácticas, el derrotero de las ideas seguirá no obstante constituyendo un insumo irrenunciable del análisis arendtiano. Y prueba de ello, es precisamente que le dedique algunas páginas a las ideas románticas que contribuyeron al pensamiento racial ${ }^{68}$ en la segunda parte del libro sobre el imperialismo, así como en la primera

\footnotetext{
${ }^{63}$ Ibíd.

${ }^{64}$ ARENDT, Hannah. "La Ilustración y la cuestión judía”. En La tradición oculta, p. 119.

65 ARENDT, Hannah. The Origins of Totalitarianism, p. 32. Traducción castellana, p. 80.

${ }^{66}$ Op. cit., p. 60. Traducción castellana, p. 112.

${ }^{67}$ Este análisis no deja de ser filosófico por sus pretensiones y sus alcances. Aunque Arendt rechace que su actividad pueda ser catalogada como filosofía, consideramos que su obra antes que una negación de la filosofía, más bien implica una reconsideración profunda de la tradición filosófica en general, y de la corriente del idealismo alemán, en particular. Quisiéramos al respecto señalar que Arendt establece un vínculo entre el romanticismo alemán y el idealismo absoluto de Hegel criticando "la orgía de pensamiento especulativo que se produjo después de que Kant liberara la necesidad de la razón de pensar más allá de la capacidad cognitiva del intelecto", en La vida del espiritu. MCCARTHY, Mary (ed.). Trad. C. Corral y F. Birulés. Buenos Aires: Paidós, 2002, p. 431.

${ }^{68}$ No se trata de concebir al racismo como producto del pensamiento racial, sino de esclarecer este fenómeno a partir del cúmulo de ideas y de prácticas que confluyen en el mismo. En el plano de las ideas Arendt destaca el papel del Romanticismo, mientras que del plano material se concentra en las prácticas segregativas propias del imperialismo europeo en las colonias de ultramar. El imperialismo necesitaba de la noción de raza para legitimar sus matanzas administrativas y generar unidad y sentido de pertenencia entre las élites dominantes en las colonias. "El imperialismo habría necesitado la invención del racismo como la única 'explicación' posible y la única excusa por sus hechos, aunque no hubiera existido el pensamiento racial en el mundo
} 
parte del libro se había ocupado en un par de páginas del papel de la Ilustración respecto del antisemitismo.

La insistencia en el origen tribal común como una esencia de la nacionalidad, que formularon los nacionalistas alemanes durante y después de la guerra de 1814, y el énfasis de los románticos en la personalidad innata y la nobleza natural, prepararon intelectualmente el camino al pensamiento racial en Alemania. ${ }^{69}$

Asimismo, podemos aseverar que su análisis del Romanticismo en Los orígenes del totalitarismo, viene a reforzar de alguna manera su concepción previa, en la medida en que sostiene que no sólo mantiene estrechos vínculos con el antisemitismo, sino también con el pensamiento racial. Bernstein advierte que el antisemitismo se vuelve verdaderamente peligroso y destructivo cuando se vuelve el foco de las ideologías raciales ${ }^{70}$. De manera que no puede subestimarse el papel del Romanticismo al haber embonado la estrecha concepción ilustrada de los otros y el antisemitismo con el pensamiento racial. En este sentido, resulta difícil poder ocultar "el origen romántico-germánico" del moderno pensamiento racial, y de ahí el peligro y la "irresponsabilidad inherente a las opiniones románticas"71.

Por eso, Arendt se aboca a la elucidación de las implicancias sociales y políticas del Romanticismo en el apartado: "Unidad de raza como sustitutivo de la emancipación nacional"72. De este modo, el hecho decisivo fue cuando la burguesía comenzó a utilizar la personalidad y el genio como características naturales que le permitía a la vez diferenciarse y despreciar a otros pueblos, en particular a los judíos. Con este proceder estaba al mismo tiempo sentando bases propicias para la conformación y propagación del pensamiento racial. Así, Arendt parece haber redoblado su apuesta respecto del Romanticismo, al expandir sus desventuradas contribuciones más allá del antisemitismo, hacia el horizonte más amplio del pensamiento racial.

\section{CONSIDERACIONES FINALES}

La Ilustración, como movimiento cultural, abraza y promueve la asimilación de los judíos, impulsada por un "nuevo humanismo"73 que impregna la atmósfera ilustrada y que atraviesa también a la corriente romántica. Cuando Herder concibe a los judíos como "especímenes de humanidad" 74 entiende que incluso al interior de este pueblo atrasado es posible encontrar rastros de humanidad que mostrarían la unidad de los seres humanos a pesar de diversidad. Esto nos permite entrever el modo de conceptualizar a los otros que subyace a la época moderna. Los

civilizado. Dado que, empero, existió el pensamiento racial, demostró ser una poderosa ayuda para el racismo" (The Origins of Totalitarianism, pp. 183-184. Traducción castellana, p. 249).

${ }^{69}$ ARENDT, Hannah. The Origins of Totalitarianism, p. 170. Traducción castellana, p. 234.

${ }^{70}$ BERNSTEIN, Richard. Hannah Arendt and the Jewish Question, p. 67.

71 ARENDT, Hannah. The Origins of Totalitarianism, p. 175. Traducción castellana, p. 239.

${ }^{72}$ Op. cit., pp. 165-170. Traducción castellana, pp. 229-234.

${ }^{73}$ Op. cit., p. 57. Traducción castellana, p. 108.

${ }^{74}$ Ibíd. 
ilustrados como propulsores de la asimilación, no estaban en realidad dispuestos a acoger a otras culturas en su seno, sino a individuos que previamente hubiesen renunciado a las peculiaridades de su procedencia, su historia y su religión. Al concebir a los individuos como entidades abstractas no sólo se soslaya la relevancia de la cultura en la constitución de la subjetividad, sino que también se obtura la posibilidad de realizarse puesto que nadie puede hacerlo en tanto ser genérico. Los judíos eran así llamados a liberarse del judaísmo para asimilarse no a un modo de ser genérico, sino a la cultura ilustrada que recreaba en su seno las motivaciones religiosas del cristianismo y se encontraba impregnada del antisemitismo imperante en la sociedad. A la idea de ser humano genérico de la Ilustración subyace la concepción del tipo de hombre que esta tradición promueve, y la exigencia de que para adherir a la misma es necesario emanciparse de la cultura de origen. Sin embargo, el "otro" vuelto un ser humano genérico ya no es otro, sino alguien indistinguible pero que tiene la marca de haber dejado de ser quién era. De este modo, los ilustrados demandaban a los judíos que renuncien a su identidad como tales, y al exaltarlos como excepciones modélicas de humanidad, los presentaban como lo exótico que puede ser normalizado, constituyendo esta exaltación una contraparte sumamente próxima de aquellas que los estigmatizan por considerarlos inferiores.

Los románticos retomarán esa idea de ciertos rasgos naturales e innatos para concebir la personalidad de los individuos y también la de los pueblos. La ascendente burguesía encontrará así la forma de disputar los privilegios de la nobleza remitiendo a cualidades naturales, al tiempo que seguirá la misma vía para adscribir a otros pueblos considerados inferiores, todas las cualidades negativas que los nobles asociaban a la burguesía. El romanticismo alemán con su exaltación de la personalidad innata y la distinción jerárquica entre pueblos basada en la naturaleza, se encuentra a la base del pensamiento racial moderno. El derrotero desde la concepción del otro de la Ilustración que exalta o estigmatiza a lo diferente sin permitirle asimilarse a no ser que se renuencia a la singularidad, deriva así entre los pensadores románticos en un pensamiento racial que jerarquiza a los individuos y pueblos en función de sus supuestas virtudes naturales.

En este contexto, la crítica de Arendt alcanza a las corrientes intelectuales de la Ilustración y del Romanticismo pero también a la tradición liberal subyacente con sus presupuestos respecto de la "humanidad" entendida en términos abstractos y desarraigados, que también se encuentra a la base de las instituciones del Estado nación. El humanismo acarrea así una paradoja estructural que proclama un modo de ser genérico y universal, pero impone la asimilación a una forma concreta de existencia del europeo, ilustrado, varón, blanco. El humanismo no sólo no puede erigirse en un dique de contención frente al totalitarismo, sino que incluso acarrea dos supuestos que embonan con el mismo: tras la fachada de un modo de ser genérico impone el modo de ser europeo dominante, a la vez que concibe la idea de humanidad en términos naturales y no como un asunto político. Este recorrido nos ha permitido advertir que el "final del humanismo"75 proclamado con

75 ARENDT, Hannah. Denktagebuch 1950 bis 1973, p. 558, XXI, 84. Traducción castellana: Diario filosófico 1950-1973, p. 541, XXI, 84 
posterioridad por Arendt en su Diario filosófico, y que recorre su libro sobre la vida activa, se origina fundamentalmente por factores intrínsecos a esa tradición vinculados a su modo de concebir al ser humano y su forma de tratar las diferencias oscilando entre disolución y la naturalización. Serán los acontecimientos del siglo pasado -Auschwitz y la bomba atómica- los que consumen el final del humanismo, aunque el mismo ya se encontraba anunciado en el carácter problemático y paradójico de sus propias concepciones del ser humanos y de los otros.

\section{REFERENCIAS BIBLIOGRÁFICAS}

ARENDT, Hannah. Essays in Understanding 1930-1950. Formation, Exile, and Totalitarianism. KOHN, Jerome (ed.). New York: Schocken Books, 1994. Traducción castellana: Ensayos de comprensión 19301954. Trad. de Agustín Serrano de Haro. Madrid: Caparrós, 2005.

. The Human Condition. Chicago: Chicago University Press, 1998. Traducción castellana: La condición bumana, trad. de Ramón Gil Novales, Barcelona, Paidós, 2001.

The Origins of Totalitarianism. New York: Harvest Books, 1979. Traducción castellana: Los orígenes del totalitarismo. Trad. de Guillermo Solana. Madrid: Taurus, 1999.

2000.

Raher Varnhagen. Vida de una mujer judía. Trad. de Daniel Najmías. Barcelona: Lumen, Paidós, 2002.

La vida del espiritu. MCCARTHY, Mary (ed.). Trad. C. Corral y F. Birulés. Buenos Aires:

. Denktagebuch 1950 bis 1973. LUDZ, Ursula y NORDMANN, Ingeborg (eds.). Münich: Piper, 2002. Traducción castellana: Diario filosófico 1950-1973. Trad. de Raul Gabás. Barcelona: Herder, 2006.

La tradición oculta. Trad. de R. S. Carbó y V. Gómez Ibañez. Buenos Aires: Paidós, 2004.

The Jewish Writings. KOHN, Jerome y FELDMAN Ron H. (eds.). New York: Schoken Books, 2007. Traducción castellana: Escritos judíos. Trad. de Miguel Cancel, R. S. Cargó, Vicente Gómez Ibáñez y Eduardo Cañas. Madrid: Paidós, 2009.

y JASPERS, Karl. Hannah Arendt and Karl Jaspers. Correspondence 1926-1969. Trad. de Robert and Rita Kimber. New York: Harvest Book, 1993.

BACCI, Claudia. “¿Puede lo personal ser político?”. En: Deus Mortalis. Cuaderno de Filosofía Politica. Buenos Aires: n. 7, 2008, pp. 179-196.

BENHABIB, Seyla. The Reluctant Modernism of Hannah Arendt. Walnut Creek: Altamira Press, 2000.

"La paria y su sombra: la biografía de Hannah Arendt sobre Rahel Varnhagen". En BIRULES, Fina (comp.). Hannah Arendt. El orgullo de pensar. Trad. de Javier Calvo Perales. Barcelona: Gedisa, 2000, pp. 97-115.

“"El derecho a tener derechos» Hannah Arendt y las contradicciones del Estado-nación”. En El derecho de los otros. Extranjeros, residentes y ciudadanos. Trad. de Gabriel Zadunaisky. Barcelona: Gedisa, 2005, pp. 45-60.

BERNSTEIN, Richard. Hannah Arendt and the Jewish Question. Cambridge: Polity Press and Blackwell Publishers, 1996. 
CANOVAN, Margaret. Hannah Arendt. A Reinterpretation of her Political Thought. Cambridge: Press Syndicate of the University of Cambridge, 2002.

DI PEGO, Anabella. La modernidad en cuestión. Totalitarismo y sociedad de masas en Hannah Arendt. La Plata: Edulp, 2015.

HEUER, Wolfgang, HEITER, Bernd y ROSENMÜLLER, Stefanie. Arendt Handbuch. Leben, Werk, Wirkung. Berlin: Metzler, 2011.

KARCZMARCZYK, Pedro. Gadamer: aplicación y comprensión. La Plata: Edulp, 2007.

KOHN, Jerome. "Una vida judía: 1906-1975”. En: ARENDT, Hannah. Escritos judíos. KOHN, Jerome y FELDMAN, Ron H. (eds.). Paidós: Madrid, 2009.

KRISTEVA, Julia. El genio femenino. Hannah Arendt. Trad. de Jorge Piatogorsky. Buenos Aires: Paidós, 2003.

LÖWY, Michel y SAYRE, Robert. Rebelión y melancolia. El romanticismo como contracorriente de la modernidad, trad. de Graciela Montes, Buenos Aires, Nueva Visión, 2008.

NOVO, Rita. Hannah Arendt. El relato sobre Rabel Varnhagen. Mar del Plata: Eudem, 2011.

SWIFT, Simon. Hannah Arendt, London, Routledge, 2009.

TRAVERSO, Enzo. La historia desgarrada. Ensayo sobre Auscbwitzy los intelectuales. Trad. de David Chiner. Barcelona: Herder, 2001. Aires: FCE, 2003.

La violencia nazi. Una genealogía europea. Trad. de Beatriz Horrac y Martín Dupaus. Buenos

Los judios y Alemania. Ensayos sobre la "simbiosis judio-alemana".Trad. de Isabel Sancho García. Valencia: Pre-textos, 2005.

VILLA, Dana. Arendt and Heidegger. The Fate of the Political. New Jersey: Princeton University Press, 1996.

Politics, Philosophy, Terror. Essays on the Thought of Hannah Arendt. New Jersey: Princeton University Press, 1999.

YOUNG-BRUEHL, Elisabeth. Hannah Arendt. Trad. de Manuel Lloris Valdés. Valencia: Alfons el magnànim, 1993. 